\title{
Erythronium japonicum attenuates histopathological lung abnormalities in a mouse model of ovalbumin-induced asthma
}

\author{
JI-HYE SEO ${ }^{1,4^{*}}$, MI-AE BANG $^{2 *}$, GYEYEOP KIM $^{3 *}$, SEUNG SIK CHO ${ }^{4}$ and DAE-HUN PARK ${ }^{1}$ \\ ${ }^{1}$ Department of Oriental Medicine Materials, Dongshin University, Naju, Jeonnam 58245; \\ ${ }^{2}$ R\&D Team, Jeonnam Bioindustry Foundation, Food Research Institute (JBF-FRI), Naju, Jeonnam 58275; \\ ${ }^{3}$ Department of Physical Therapy, Dongshin University, Naju, Jeonnam 58245; ${ }^{4}$ College of Pharmacy, \\ Mokpo National University, Mokpo, Jeonnam 588554, Republic of Korea
}

Received October 6, 2015; Accepted March 21, 2016

DOI: $10.3892 /$ ijmm.2016.2541

\begin{abstract}
Asthma is a chronic lung condition that can induce mucus hypersecretion and pulmonary obstruction and may even cause death, particularly in children and older individuals. Erythronium japonicum (E.japonicum) is a traditional herb used in Korea and East Asian countries that has been found to exert free radical scavenging activity and anti-proliferative effects in human colorectal carcinoma cells. In the present study, we evaluated the anti-asthmatic effects of an extract of E. japonicum in a mouse model of ovalbumin (OVA)-induced asthma. Female BALB/c mice were sensitized with an intraperitoneal injection of OVA and aluminum hydroxide hydrate on days 1 and 8 and then received the following treatments on days 21 to 25 : i) control (no treatment), ii) sterilized tap water (given orally), iii) $1 \mathrm{mg} / \mathrm{kg} /$ day dexamethasone (administered orally), iv) $60 \mathrm{mg} / \mathrm{kg} /$ day $E$. japonicum extract, and v) $600 \mathrm{mg} / \mathrm{kg} /$ day E.japonicum extract. On the same days, all the mice except those in the control group were challenged $1 \mathrm{~h}$ later with nebulized 5\% OVA for $30 \mathrm{~min}$. We found that treatment with E.japonicum extract suppressed the OVA-induced increase in the number of white blood cells and decreased the IgE level in the bronchoalveolar lavage fluid samples obtained from the mice. Histopathological analysis of the lung tissues revealed that E. japonicum attenuated the asthma-related morphological changes in the mouse lung tissue, including the increased secretion of mucus in the bronchioles, eosinophil infiltration around the bronchioles and vessels, and goblet cell and epithelial cell hyperplasia. Immunohistochemical analysis revealed that treatment with $E$. japonicum extract suppressed the OVA-induced proliferation of $\mathrm{T}$ helper
\end{abstract}

Correspondence to: Dr Dae-Hun Park, Department of Oriental Medicine Materials, Dongshin University, Naju, Jeonnam 58245, Republic of Korea

E-mail:dhj1221@paran.com

*Contributed equally

Key words: Erythronium japonicum, ovalbumin-induced asthma, interferon- $\gamma$, interleukin-4, interleukin-5 cells $\left(\mathrm{CD}^{+}\right)$and $\mathrm{B}$ cells $\left(\mathrm{CD} 19^{+}\right)$in the mouse lung tissue. Furthermore, treatment with E.japonicum extract modulated the expression of both $\mathrm{T}$ helper 2 cell-related factors [GATA binding protein 3 (GATA-3), tumor necrosis factor- $\alpha$ (TNF- $\alpha$ ), interleukin (IL)-4, IL-5, IL-6 and IL-13], as well as that of T helper 1 cell-related factors [(interferon- $\gamma($ IFN- $\gamma)$ IL-12p35 and IL-12p40]. These findings suggest that E.japonicum may potentially be used as an anti-asthmatic treatment.

\section{Introduction}

The World Health Organization estimates that 235 million individuals worldwide suffered from asthma in 2013 (1). In the United States, an estimated 25.9 million individuals, including almost 7.1 million children, suffered from asthma in 2013, and asthma was the third most common cause of hospitalization for children under 15 years of age (2). The symptoms of asthma are difficult to control (3), and its causes are diverse, including hereditary factors and external factors, such as pet dander, dust mites, cockroaches, viral infections, pollen, mold, fungi and tobacco smoke (1). The typical manifestations of asthma vary from a cough to obstructive apnea, which may arise due to the excessive production of mucus, goblet cell hyperplasia, epithelial cell shedding, basement membrane thickening, as well as eosinophil and lymphocyte infiltration $(4,5)$.

Asthma is a chronic lung condition that involves an imbalance between $\mathrm{T}$ helper (Th)1- and Th2-related factors $(4,5)$, including interleukin (IL)-12, interferon- $\gamma$ (IFN- $\gamma$ ), IL-4, IL-5, IL-13, IL-6 and tumor necrosis factor- $\alpha$ (TNF- $\alpha)$. IL-12 modulates the induction of Th1-specific immune responses and the suppression of Th2-specific immune responses $(6,7)$. IFN- $\gamma$ is known to stimulate the Th1 transcription factor, T-bet, resulting in a positive feedback loop between IFN- $\gamma$ and Th1 $(8,9)$. The cytokines, IL-4 and IL-13, play important roles in asthma (10). IL-4 regulates the immunoglobulin class switching from IgG to $\mathrm{IgE}$, attracts eosinophils into the interspace of pulmonary cells (11), and is involved in the induction of the Th2 transcription factor GATA-3 $(12,13,15)$. IL-13 activates B cells and induces asthma-related changes, such as the excessive production of mucus, goblet cell hyperplasia, epithelial cell shedding, basement membrane thickening, and eosinophil and lymphocyte infiltration $(14,16,17)$. Both IL-5 and IL-6 have been demonstrated to 
regulate the development, activation, migration and survival of eosinophils $(6,18)$. Furthermore, TNF- $\alpha$ is known to recruit granulocytes and to induce the proliferation of fibroblasts (19).

The drugs currently used to treat asthma include corticosteroids, bronchodilators, leukotriene modifiers, theophylline and anti-IgE agents; however, their therapeutic effects are not completely understood (20). Although inhaled corticosteroids are the most widely used therapy for suppressing the symptoms of asthma (21), they are associated with many adverse effects, including growth inhibition in children during the first year of treatment (22), cataracts and glaucoma, hypertension, hyperlipidemia, peptic ulcers, myopathy and immunosuppressive effects (23). Thus, the unwanted side-effects of corticosteroids have increased the need to develop anti-asthmatic drugs from natural products.

Erythronium japonicum (E. japonicum) is an indigenous herb in Korea and East Asian countries (24). It is distributed throughout Hokkaido in Japan, where the starch ('katakuriko' in Japanese) is obtained from the bulb after a long, cold winter. Although a limited number of studies have explored its potentially therapeutic effects, E. japonicum extract was found in one study to possess 2,2-diphenyl-1-picrylhydrazyl free radical scavenging activity and to exert anti-proliferative effects in human colorectal carcinoma cells (25). In the present study, we evaluated the effects of E.japonicum extract on ovalbumin (OVA)-induced asthma in mice.

\section{Materials and methods}

Plant material and preparation of $80 \%$ EtOH extract. During May 2013,E.japonicum was collected from a site situated close to Wolchul mountain in the southern part of Korea. A sample was deposited at the Jeonnam Biofood Technology Center (identification number: JBF-FRI-S-2013-0099). E. japonicum was dried in a dark, cool room. Dried E. japonicum $(2 \mathrm{~kg})$ was chopped and then extracted twice with $80 \%$ aqueous EtOH (30 liters) at room temperature for $24 \mathrm{~h}$. The EtOH extracts of E.japonicum were concentrated and evaporated under a vacuum. E. japonicum extract was analyzed using high-performance liquid chromatography (HPLC).

Establishment of a mouse model of OVA-induced asthma. Female BALB/c mice ( 5 weeks old, $n=80$ ) were purchased from Samtako Korea (Osan, Korea) and randomly divided into the following 5 treatment groups: i) the control group (no treatment, no OVA challenge); ii) the group administered sterilized tap water and challenged with OVA; iii) the group administered $1 \mathrm{mg} / \mathrm{kg} /$ day dexamethasone followed by OVA challenge; iv) the group administered $60 \mathrm{mg} / \mathrm{kg} / \mathrm{day}$ E. japonicum extract followed by OVA challenge; and v) the group administered $600 \mathrm{mg} / \mathrm{kg} /$ day E.japonicum extract followed by OVA challenge. On days 1 and 8 , all mice were sensitized with an intraperitoneal injection of $20 \mu \mathrm{g}$ OVA and $1 \mathrm{mg}$ aluminum hydroxide hydrate (both from Sigma-Aldrich, St. Louis, MO, USA) in $500 \mu 1$ saline. On days 21 to 25 , all mice except those used as controls were challenged once daily with 5\% OVA for $30 \mathrm{~min}$ using a nebulizer $(3 \mathrm{ml} / \mathrm{min}$, NE-U17; Omron Co. Ltd., Kyoto, Japan). During the same 5-day period, the mice in the treatment groups were also treated once daily with oral doses of either sterilized tap water, dexamethasone, or 60 or
$600 \mathrm{mg} / \mathrm{kg} /$ day E. japonicum extract (hereafter referred to as E. japonicum) $1 \mathrm{~h}$ prior to the OVA challenge.

Ethics statement. E. japonicum was collected on private land with permission granted by the owner. All experiments were approved by the Institutional Animal Care and Use Committee at Dongshin University (approval no. 2014-08-04).

Analysis of bronchoalveolar lavage fluid $(B A L F)$. One day after the final treatment, the mice were anesthetized with intraperitoneal injections of $50 \mathrm{mg} / \mathrm{kg}$ Zoletin (Virbac, Fort Worth, TX, USA), and thereafter the tracheas were cannulated with disposable animal feeding needles. Lavages were performed with three $0.4 \mathrm{ml}$ aliquots of cold phosphate-buffered saline (PBS). The BALF samples were collected and immediately centrifuged at 3,000 rpm for $5 \mathrm{~min}$ (Sorvall Legend Micro 17R; Thermo Fisher Scientific, Inc., Marietta, OH, USA). The cell pellets were resuspended in PBS in order to determine the total and differential white blood cell (WBC) counts. The numbers of total and differential cells were counted using the Hemavet Multispecies Hematology System (Drew Scientific, Inc., Waterbury, CT, USA) (n=8/group). The levels of IgE in the BALF were measured using a specific mouse IgE enzymelinked immunosorbent assay kit (Abnova, Atlanta, GA, USA), according to the manufacturer's instructions ( $n=8 /$ group).

Histopathological analysis. One day after the final treatment, the mice were anesthetized with intraperitoneal injections of $50 \mathrm{mg} / \mathrm{kg}$ Zoletin and lung tissue was obtained. The mice were then sacrificed by exsanguination. The lung tissue was fixed in $10 \%(\mathrm{v} / \mathrm{v})$ formaldehyde solution, dehydrated in a graded ethanol series $(99.9,90,80$ and 70\%), and embedded in paraffin. The paraffin-embedded lung tissue was then sectioned (4- $\mu$ m-thick sections) longitudinally and stained with hematoxylin and eosin. The sections were also stained with Periodic acid-Schiff for the semi-quantitative analysis of glycoproteins.

Immunohistochemical analysis. The deparaffinized tissue sections were treated with $3 \%$ hydrogen peroxide in methanol for $10 \mathrm{~min}$ to remove the endogenous peroxidase. Antigen retrieval was performed with sodium citrate buffer $(0.1 \mathrm{M})$ using the microwave method. The slides were incubated with normal serum to block non-specific binding and then incubated overnight at $4^{\circ} \mathrm{C}$ with the following primary antibodies (diluted 1:100 to 1:200): rat anti-mouse CD4 monoclonal (14-9766; eBioscience, San Diego, CA, USA); rat anti-mouse CD8 monoclonal (sc-18913; Santa Cruz Biotechnology, Inc., Santa Cruz, CA, USA); rabbit anti-mouse CD19 polyclonal (250585; Abbiotec, San Diego, CA, USA); rabbit anti-mouse Tbx21/T-bet polyclonal (bs-3599R; Bioss, Woburn, MA, USA); goat anti-mouse GATA-3 (TA305795; OriGene, Rockville, MD, USA); rat anti-mouse IFN- $\gamma$ monoclonal (sc-74104), goat anti-mouse IL-12p35 polyclonal (sc-9350) and rat anti-mouse IL-12p40 monoclonal (sc-57258) (all from Santa Cruz Biotechnology, Inc.); rabbit anti-mouse TNF- $\alpha$ polyclonal (3053R-100; BioVision, Milpitas, CA, USA); rat anti-mouse IL-4 monoclonal (sc-73318) and rabbit anti-mouse IL-5 polyclonal (sc-7887) (both from Santa Cruz Biotechnology, Inc.); rabbit anti-mouse IL-6 polyclonal (PAB16165; Abnova, Taipei City, Taiwan), and goat anti-mouse IL-13 polyclonal 

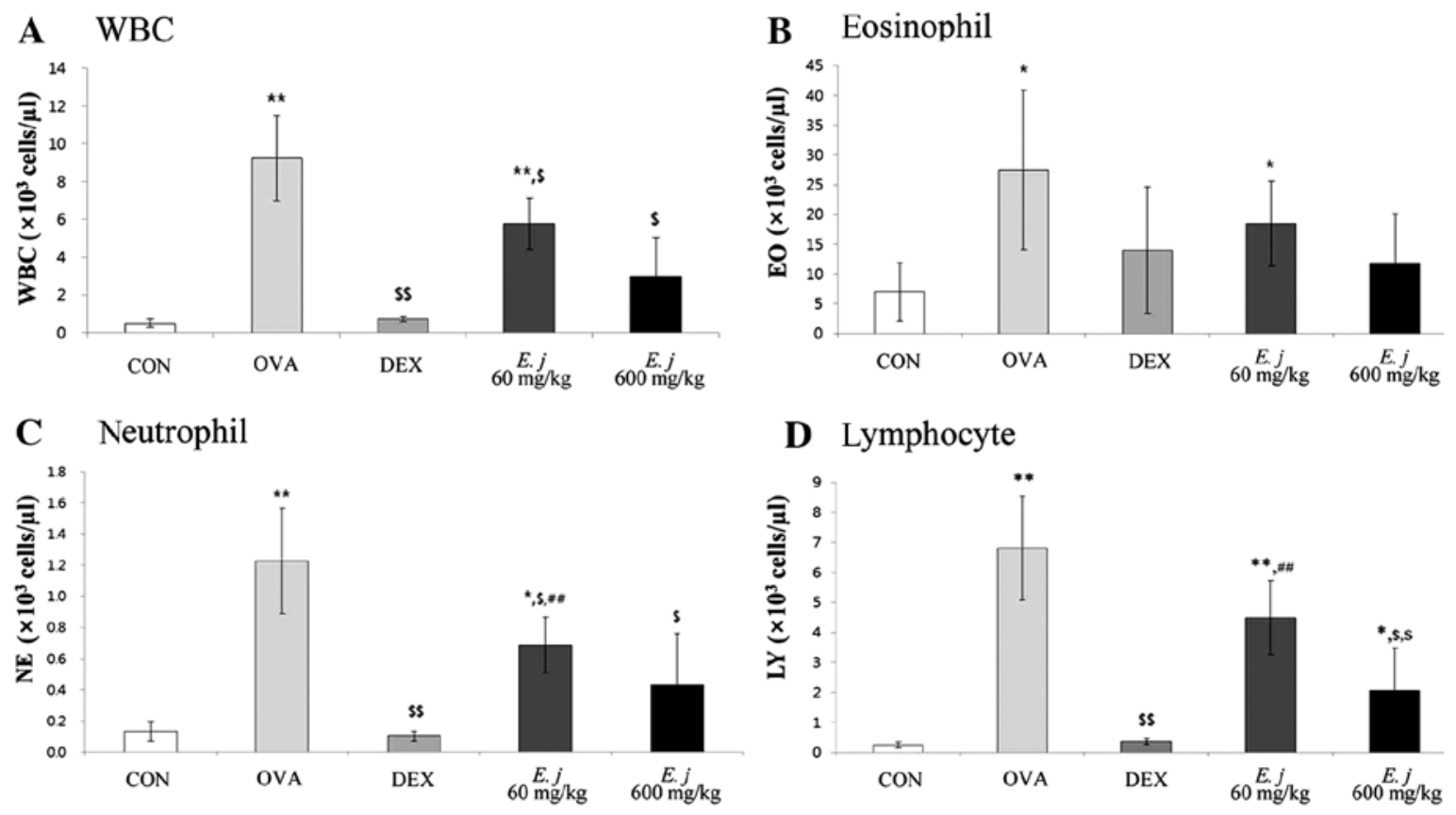

D Lymphocyte
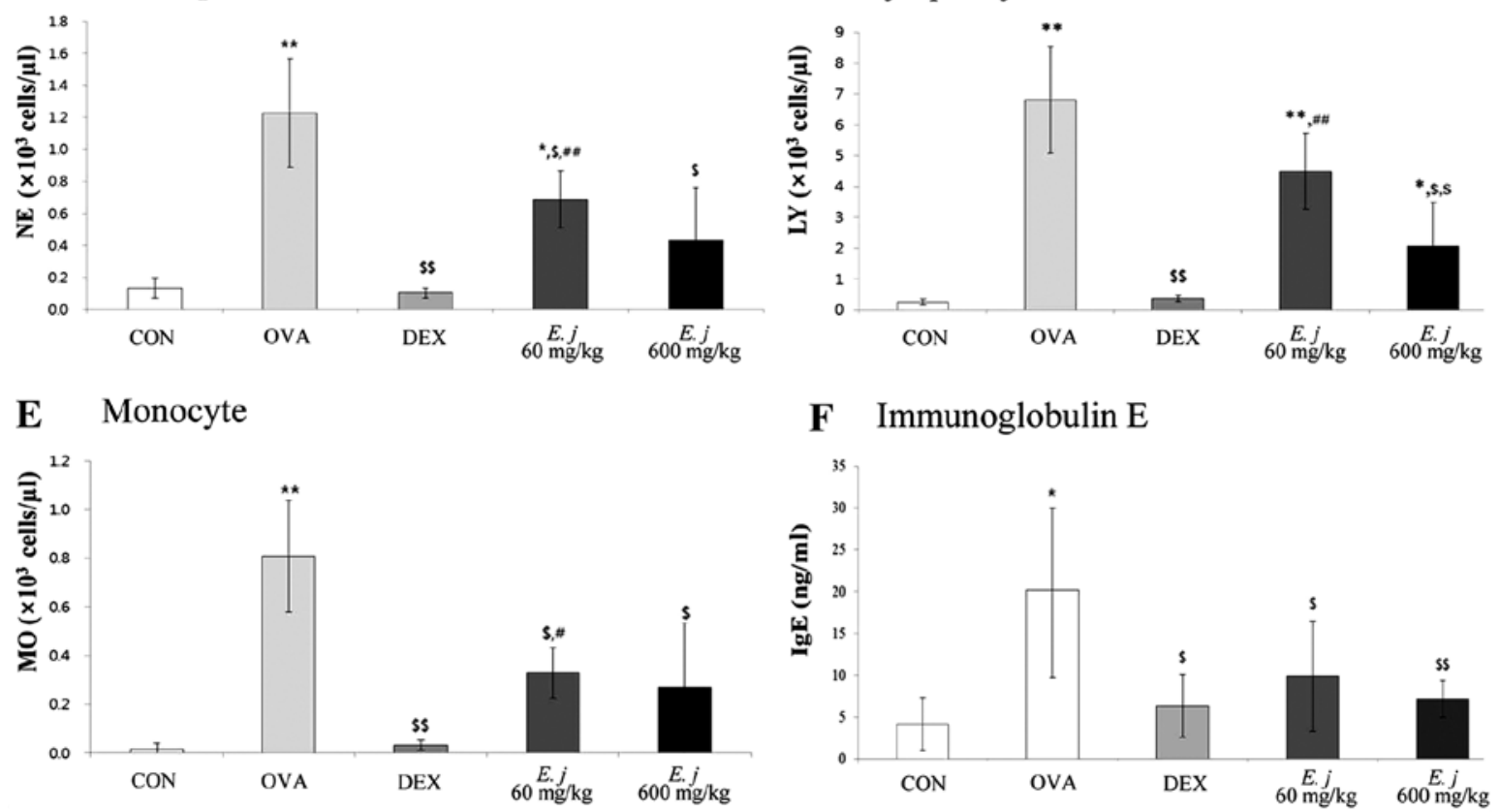

Figure 1. Effects of E. japonicum on the total and differential white blood cell (WBC) counts as well as IgE levels in the bronchoalveolar lavage fluid (BALF) samples. (A) Number of WBCs. (B) Number of eosinophils (EO). (C) Number of neutrophils (NE). (D) Number of lymphocytes (LY). (E) Number of monocytes (MO). (F) Level of immunoglobulin E (IgE). CON, control; OVA, ovalbumin; DEX, dexamethasone; E.j, E. japonicum. " p $<0.05$ vs. CON; * ${ }^{* *}<0.001$ vs. CON; ${ }^{\text {p }}<0.05$ vs. OVA; ${ }^{\$ \$} \mathrm{p}<0.001$ vs. OVA; ${ }^{\#} \mathrm{p}<0.05$ vs. DEX; ${ }^{\# \#} \mathrm{p}<0.001$ vs. DEX.

(sc-1776; Santa Cruz Biotechnology, Inc.) antibodies. Subequently, the slides were incubated for $2 \mathrm{~h}$ with biotinylated secondary antibody (1:500; Dako, Carpinteria, CA, USA) and horseradish-peroxidase conjugated streptavidin. Signals were detected using 3,3-diaminobenzidine tetrahydrochloride substrate chromogen solution, and the cells were counterstained with Mayer's hematoxylin. To determine the number of positively stained cells, we counted the cells in 5 randomly selected, non-overlapping fields (magnification, $\mathrm{x} 200$ ) from 3 separately immunostained lung sections per animal ( $\mathrm{n}=8 /$ group).

HPLC analysis. HPLC analysis was performed using an HPLC system (Agilent Technology, Santa Clara, CA, USA) according to the following parameters: column, Zorbax extend-C18 (4.6 $\mathrm{mm}$ inner diameter x $150 \mathrm{~mm}$ height, $5.0-\mu \mathrm{m}$ particle diameter); mobile phase, $0.2 \%$ acetic acid and methanol used as $\mathrm{A}$ and $\mathrm{B}$, respectively, with the following solvent gradient: $25 \%$ B , 0-5 min; 25-50\% B, 5-10 min; and 50-25\% B, 10-15 min; injection volume, $10 \mu \mathrm{l}$; flow rate, $1 \mathrm{ml} / \mathrm{min}$; UV detection, $330 \mathrm{~nm}$. All solvents were of extra-pure grade. Methanol and distilled water were purchased from J.T. Baker (Phillipsburg,
NJ, USA). Acetic acid, caffeic acid and chlorogenic acid were purchased from Sigma-Aldrich.

Statistical analysis. Data are shown as the means \pm standard deviation (SD). Group differences were evaluated using one-way analysis of variance followed by Dunnett's multiple comparison tests. A p-value of $<0.05$ or $<0.001$ was considered to indicate a statistically significant difference.

\section{Results}

Effects of E. japonicum on the total and differential WBC counts and on the IgE levels in the BALF samples. Compared with the BALF obtained from the control mice, the BALF collected from the OVA-challenged mice contained significantly higher numbers of total WBCs and differential WBCs (eosinophils, neutrophils, lymphocytes and monocytes), as well as significantly higher levels of IgE (Fig. 1). Treatment with both dexamethasone, a drug commonly used to suppress the symptoms of asthma, and E. japonicum significantly decreased the number of WBCs, as well as the IgE levels in the OVA-challenged mice. 


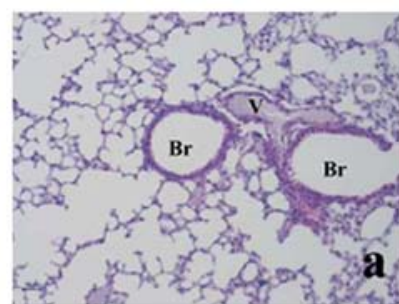

A

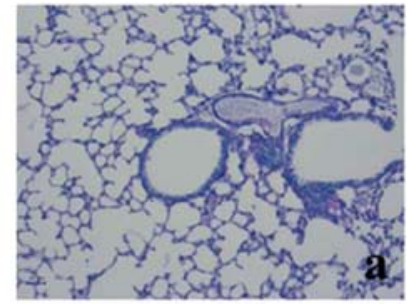

B
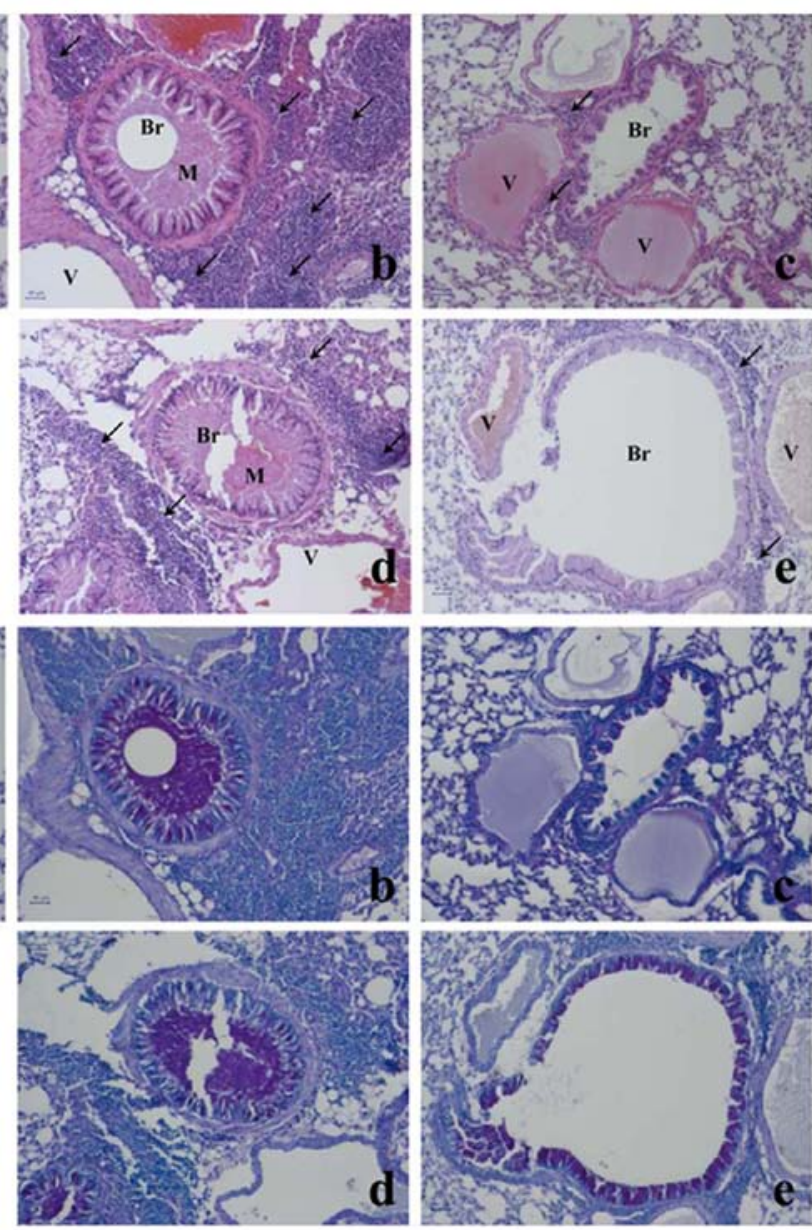

Figure 2. Effects of E. japonicum on lung tissue morphology. (A) Representative images of hematoxylin and eosin-stained lung tissue. (B) Representative images of Periodic acid-Schiff-stained lung tissue. Scale bar, $50 \mu \mathrm{m}$; arrows, eosinophil infiltration; Br, bronchiole; M, mucus secretion; V, vessel. Treatment groups: panel a, control; panel b, ovalbumin; panel c, dexamethasone; panel d, $60 \mathrm{mg} / \mathrm{kg} /$ day E.japonicum; panel e, $600 \mathrm{mg} / \mathrm{kg} / \mathrm{day}$ E.japonicum.

Effects of E. japonicum on lung tissue morphology. The asthma-related histopathological changes in the mouse lung tissues were evaluated using hematoxylin and eosin staining and Periodic acid-Schiff staining (Fig. 2). Compared with the lung tissue isolated from the control mice, the lung tissue from the OVA-challenged mice exhibited typical asthma-related changes, including goblet cell and epithelial cell hyperplasia, eosinophil infiltration around the bronchioles and vessels, as well as the increased secretion of mucus in the bronchioles, and these changes were attenuated by treatment with dexamethasone. Treatment with E. japonicum also attenuated these histopathological changes in a dose-dependent manner; $600 \mathrm{mg} / \mathrm{kg} /$ day of E. japonicum appeared to be more effective at inhibiting the OVA-induced changes in the mouse lung tissue compared with the dose of $60 \mathrm{mg} / \mathrm{kg} / \mathrm{day}$.

Effects of E. japonicum on the numbers of Th cells, T cells, and $B$ cells. The development of asthma involves an imbalance between Th1 and Th2 cells $(4,5)$. In order to evaluate the effects of E. japonicum treatment on Th cells, T cells and $\mathrm{B}$ cells, we quantified the numbers of $\mathrm{CD} 4^{+} \mathrm{Th}$ cells, $\mathrm{CD}^{+}$cytotoxic $\mathrm{T}$ cells and $\mathrm{CD} 19^{+} \mathrm{B}$ cells in the mouse lung tissue by performing immunohistochemical analysis (Fig. 3). Compared with the control mice, the lung tissue isolated from the OVA-challenged mice had significantly higher numbers of all 3 types of cells, and these increased numbers were significantly reduced by treatment with both dexamethasone and E. japonicum. Furthermore, treatment with E. japonicum exerted a reducing effect on the numbers of $\mathrm{CD}^{+} \mathrm{Th}$ cells and $\mathrm{CD} 19^{+} \mathrm{B}$ cells in a dose-dependent manner, with greater effects observed at the dose of $600 \mathrm{mg} / \mathrm{kg} /$ day compared with $60 \mathrm{mg} / \mathrm{kg} / \mathrm{day}$.

Effects of E.japonicum on the expression of T-bet and GATA-3. To examine the effects of E. japonicum treatment on Th cell transcription factors, we examined the expression of T-bet (Th1 cell transcription factor) and GATA-3 (Th2 cell transcription factor) in the mouse lung tissue by perfoming immunohistochemical analysis (Fig. 4). Compared with the control mice, the lung tissue isolated from the OVA-challenged mice exhibited a significantly higher expression of T-bet and GATA-3, and these effects were significantly reduced by dexamethasone treatment. Treatment with E. japonicum exerted a reducing effect on GATA-3 expression in a dose-dependent manner, with the dose of $600 \mathrm{mg} / \mathrm{kg} /$ day significantly reducing the OVA-induced expression of GATA-3 to a greater extent compared with the dose of $60 \mathrm{mg} / \mathrm{kg} /$ day. However, the expression of T-bet in the E.japonicum treatment groups remained at higher levels compared to the control group, and there was no significant difference between the 2 doses used. 


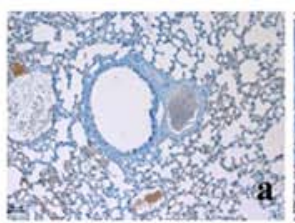

A
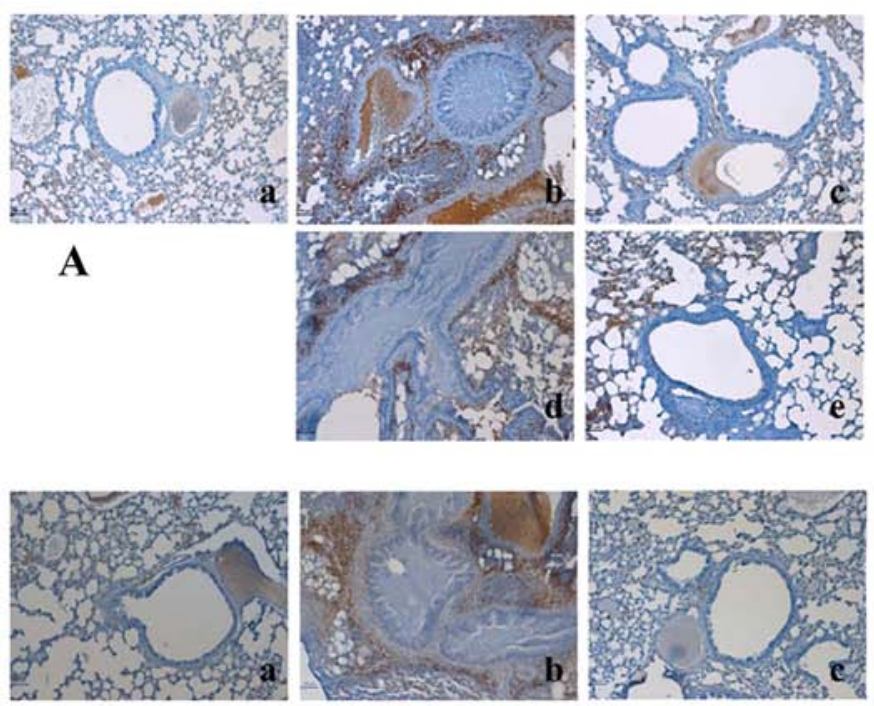

C

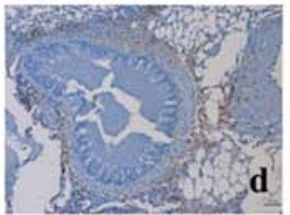

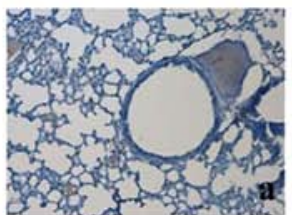

B
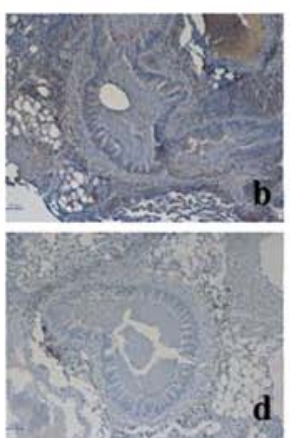

D

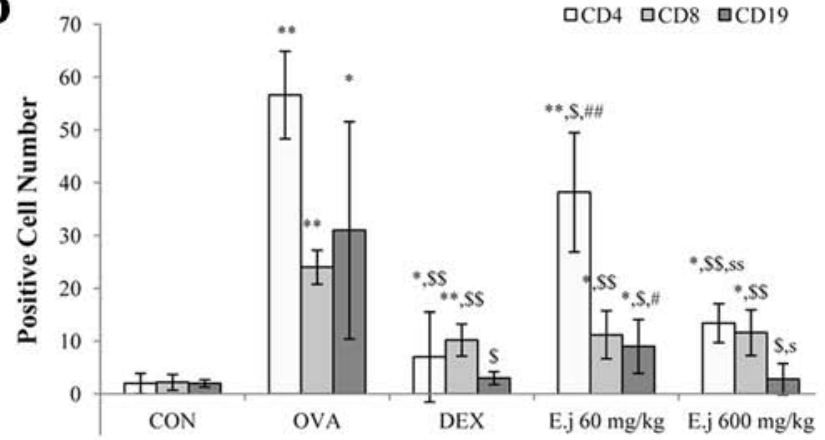

Figure 3. Effects of E. japonicum on the numbers of Th, T and B cells in mouse lung tissue. (A) Representative images of CD4 ${ }^{+}$Th cells. (B) Representative images of $\mathrm{CD}^{+}$cytotoxic T cells. (C) Representative images of CD19 ${ }^{+} \mathrm{B}$ cells. Immunopositive cells were counted in 5 randomly selected, non-overlapping fields (magnification, x200) from 3 separately immunostained lung sections per animal. Treatment groups: panel a, control (CON); panel b, ovalbumin (OVA); panel c, dexamethasone (DEX); panel d, $60 \mathrm{mg} / \mathrm{kg} / \mathrm{day}$ E. japonicum (E.j.); panel e, $600 \mathrm{mg} / \mathrm{kg} /$ day E. japonicum. (D) Quantitative analysis of positively-stained cells. " p<0.05 vs. CON; ${ }^{* *}$ p $<0.001$ vs. CON; ${ }^{\$ p}$ p $<0.05$ vs. OVA; ${ }^{\$ \$}$ p $<0.001$ vs. OVA; ${ }^{\#}$ p $<0.05$ vs. DEX; ${ }^{\# \# ~ p<0.001 ~ v s . ~ D E X ; ~}{ }^{\text {p }}<0.05$ vs. 60 mg/kg/day E.j; ${ }^{\text {ss }}$ p $<0.001$ vs. 60 mg/kg/day E.j.

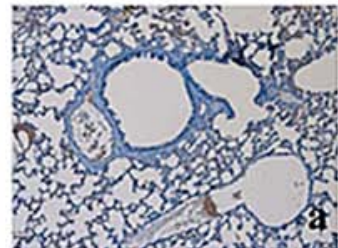

A
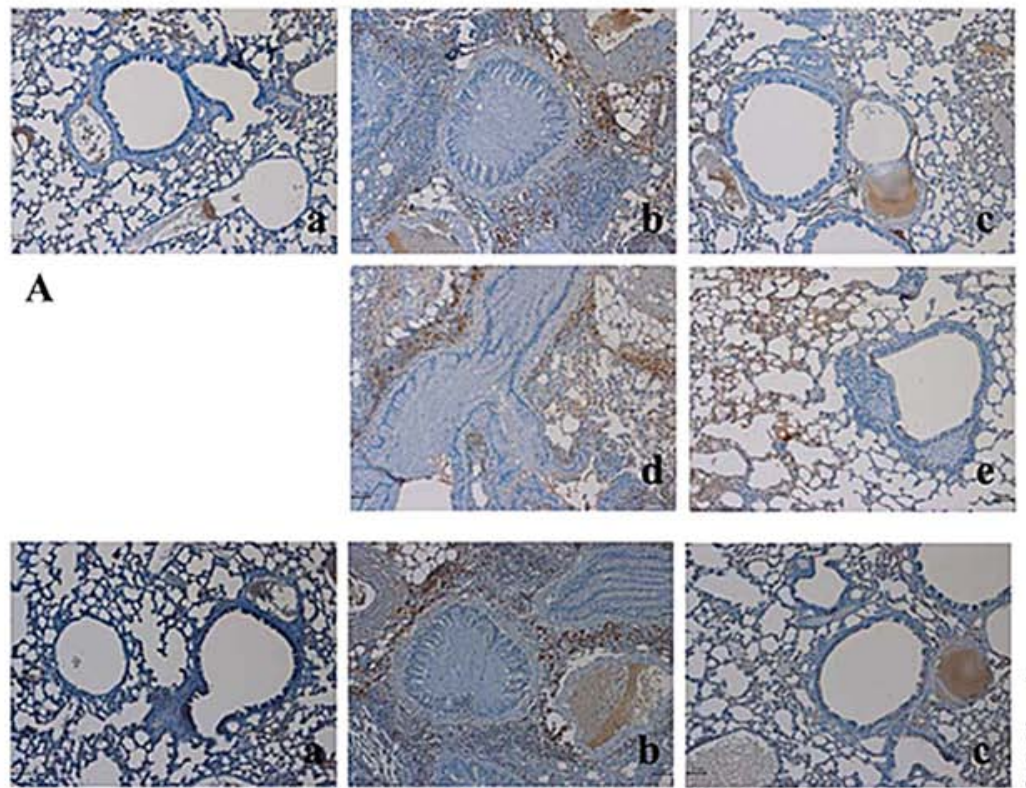

B
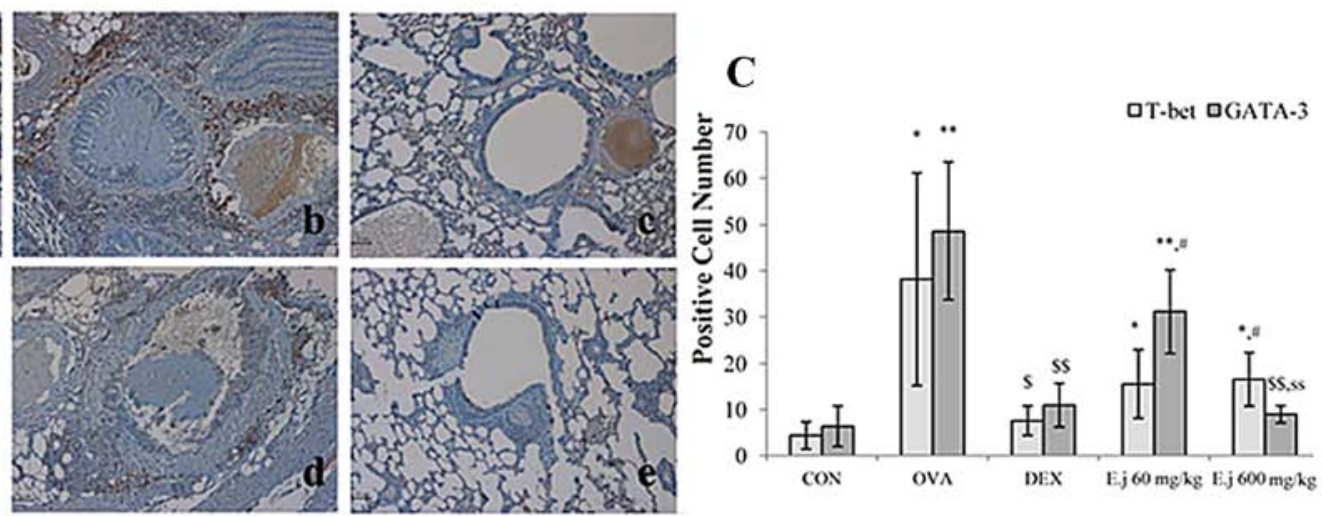

Figure 4. Effects of E. japonicum on the expression of T-bet and GATA-3 in mouse lung tissue. (A) Representative images of T-bet ${ }^{+}$cells. (B) Representative images of GATA- $3^{+}$cells. Immunopositive cells were counted in five randomly selected, non-overlapping fields (magnification, x200) from 3 separately immunostained lung sections per animal. Treatment groups: panel a, control (CON); panel b, ovalbumin (OVA); panel c, dexamethasone (DEX); panel d, $60 \mathrm{mg} / \mathrm{kg} / \mathrm{day}$ E. japonicum (E.j); panel e, $600 \mathrm{mg} / \mathrm{kg} /$ day E.j. (C) Quantitative analysis of positively-stained cells. " p $<0.05 \mathrm{vs}$. CON; ${ }^{* *} \mathrm{p}<0.001 \mathrm{vs}$. CON; ${ }^{\$}$ p $<0.05 \mathrm{vs}$. OVA; ${ }^{\$ s} \mathrm{p}<0.001$ vs. OVA; ${ }^{\mathrm{p}}<0.05$ vs. DEX; ${ }^{\mathrm{ss}} \mathrm{p}<0.001$ vs. $60 \mathrm{mg} / \mathrm{kg} / \mathrm{day}$ E.j. 


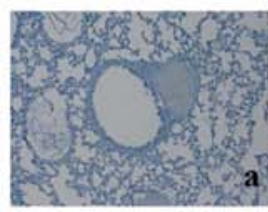

A
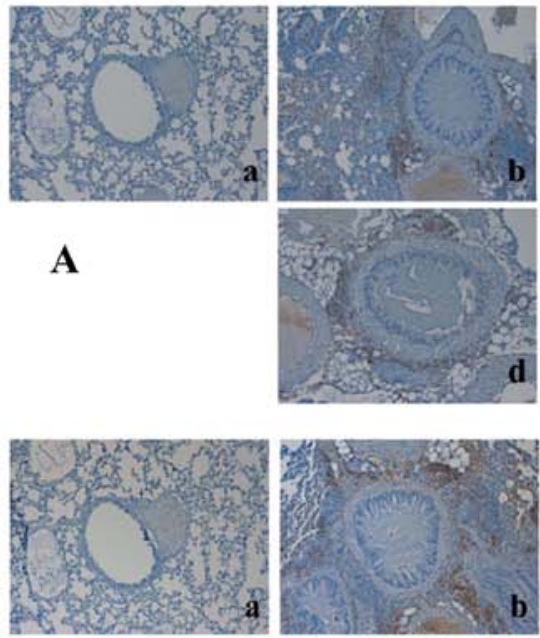

C

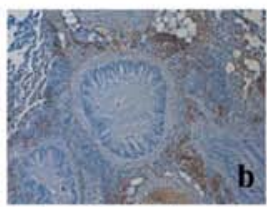

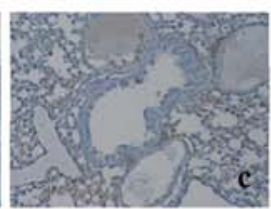
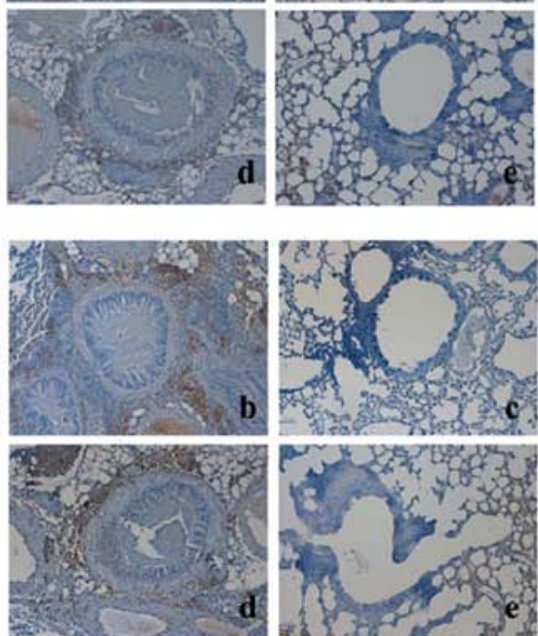

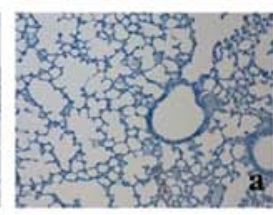

B
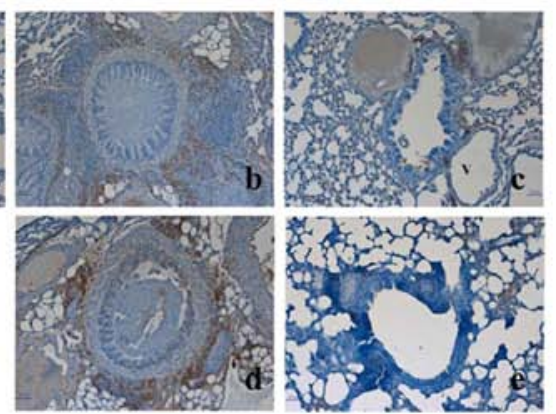

D

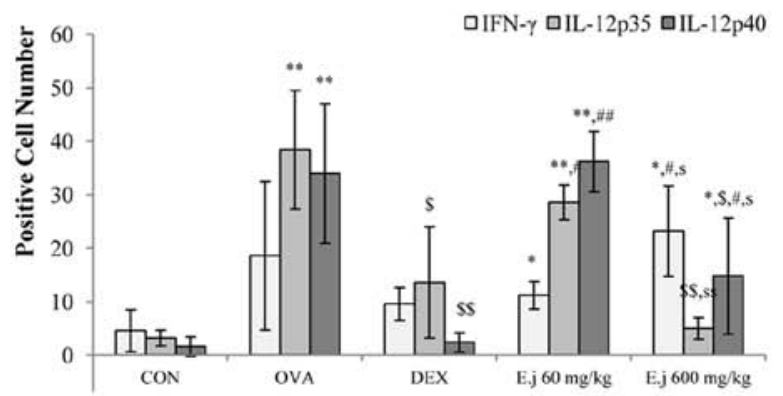

Figure 5. Effects of E. japonicum on the expression of Th1-related cytokines in mouse lung tissue. (A) Representative images of interferon- $\gamma(\text { IFN- } \gamma)^{+}$cells. (B) Representative images of interleukin (IL)- $12 \mathrm{p} 35^{+}$cells. (C) Representative images of IL-12p40 cells. Immunopositive cells were counted in 5 randomly selected, non-overlapping fields (magnification, x200) from 3 separately immunostained lung sections per animal. Treatment groups: panel a, control (CON); panel b, ovalbumin (OVA); panel c, dexamethasone (DEX); panel d, $60 \mathrm{mg} / \mathrm{kg} / \mathrm{day}$ E. japonicum (E.j); panel e, $600 \mathrm{mg} / \mathrm{kg} / \mathrm{day}$ E.j. (D) Quantitative analysis of positively-stained cells. ${ }^{*}<0.05$ vs. CON; ${ }^{* *} \mathrm{p}<0.001$ vs. CON; ${ }^{\$} \mathrm{p}<0.05$ vs. OVA; ${ }^{\$} \mathrm{p}<0.001$ vs. OVA; ${ }^{\#} \mathrm{p}<0.05 \mathrm{vs}$. DEX; ${ }^{\# \#} \mathrm{p}<0.001 \mathrm{vs.} \mathrm{DEX;}{ }^{\mathrm{p}}<0.05 \mathrm{vs}$. $60 \mathrm{mg} / \mathrm{kg} / \mathrm{day}$ E.j; ${ }^{\text {ss }}$ < 0.001 vs. $60 \mathrm{mg} / \mathrm{kg} / \mathrm{day}$ E.j.

Effects of E.japonicum on the expression of Th1-related cytokines. The imbalance between Th1 and Th2 cells which occurs in asthma involves a decrease in Th1-related cytokine levels and an increase in Th2-related cytokine levels $(4,5)$. In this study, to examine alterations in the levels of Th1-related cytokines, we measured the expression levels of IFN- $\gamma$, IL-12p35 and IL-12p40 in the mouse lung tissue (Fig. 5). Compared with the control mice, the lung tissue isolated from the OVA-challenged mice exhibited a significantly increased expression of IL-12p35 and IL-12p40, and these effects were significantly suppressed by dexamethasone treatment. E.japonicum treatment exerted a reducing dose-dependent effect on the expression of IL-12p35 and IL-12p40, with the dose of $600 \mathrm{mg} / \mathrm{kg} / \mathrm{day}$ (but not the dose of $60 \mathrm{mg} / \mathrm{kg} /$ day) significantly reducing the OVA-induced expression of IL-12p35 and IL-12p40. E. japonicum treatment at the dose of $600 \mathrm{mg} / \mathrm{kg} /$ day increased the expression of IFN- $\gamma$.

Effect of E. japonicum on the expression of Th2-related cytokines. To examine alterations in the levels of Th2-related cytokines, we measured the expression levels of TNF- $\alpha$, IL-4, IL-5, IL-6 and IL-13 in the mouse lung tissue (Fig. 5). Compared with the control mice, the lung tissue isolated from the OVA-challenged mice exhibited a significantly increased expression of all the measured cytokines, and these changes were significantly reduced by dexamethasone treatment (Fig. 6). E. japonicum treatment decreased the OVA-induced expression of most of these cytokines in a dosedependent manner. Specifically, E.japonicum treatment at the dose of $60 \mathrm{mg} / \mathrm{kg} /$ day significantly reduced the expression of IL-13, whereas treatment with E. japonicum at $600 \mathrm{mg} / \mathrm{kg} / \mathrm{day}$ significantly reduced the expression of TNF- $\alpha$, IL-4, IL-6, IL-5 and IL-13.

\section{Discussion}

In the present study, we found that treatment with E.japonicum suppressed the OVA-induced increase in the number of WBCs, as well as the IgE level in BALF. Furthermore, treatment with E. japonicum attenuated the asthma-related morphological changes which had occurred in the mouse lung tissue following exposure to OVA, including the increased secretion of mucus, eosinophil infiltration around the bronchioles and vessels, and goblet cell and epithelial cell hyperplasia. E. japonicum treatment also suppressed the OVA-induced increase in the number of Th cells (CD4 ${ }^{+}$cells), B cells $\left(\mathrm{CD} 19^{+}\right.$cells) and T cells $\left(\mathrm{CD} 8^{+}\right.$ cytotoxic cells). Furthermore, we found that E.japonicum treatment modulated the expression of not only Th2-related factors (GATA-3, TNF- $\alpha$, IL-4, IL-5, IL-6 and IL-13), but also that of Th1-related factors (IFN- $\gamma$, IL-12p35 and IL-12p40).

To identify the particular compounds in E. japonicum that may exert anti-asthmatic effects, we conducted HPLC analysis. Although not all the compounds in E.japonicum were isolated, we found that chlorogenic acid and caffeic acid were candidate compounds (Fig. 7). Chlorogenic acid is associated with lignin biosynthesis (26) and it has been demonstrated to exert several effects, including protective effects against oxidative stress-induced hepatotoxicity (27), anti-hypertensive effects (28) and the suppressive effects on several asthmarelated factors in an animal model of ovalbumin-induced asthma (29). Furthermore, chlorogenic acid is an immunoregulatory molecule (30). 


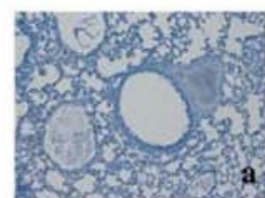

A
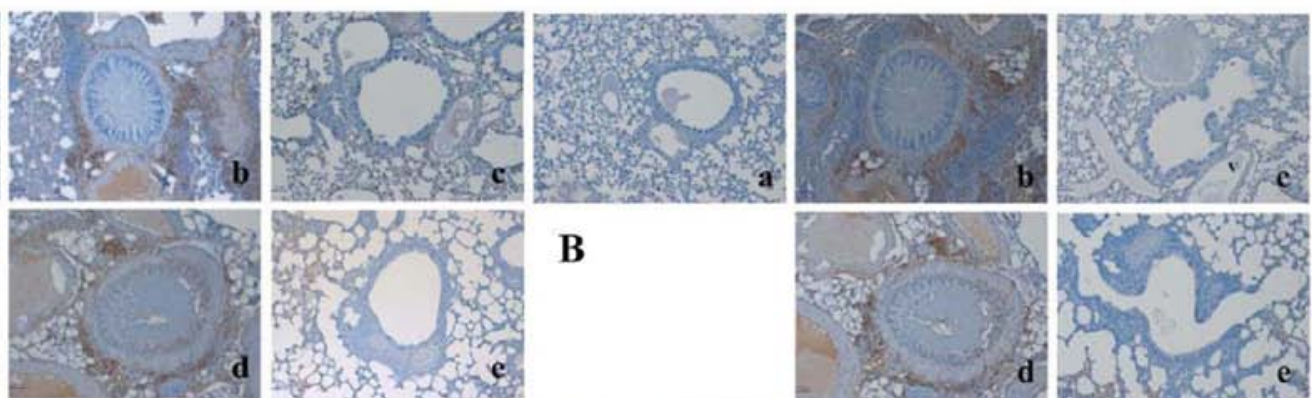

B
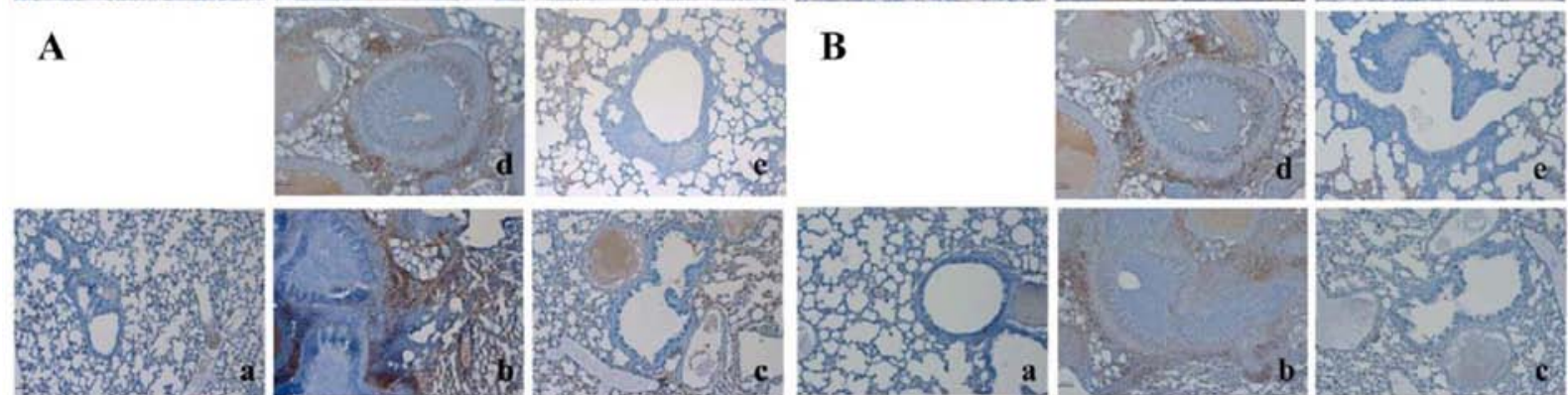

C
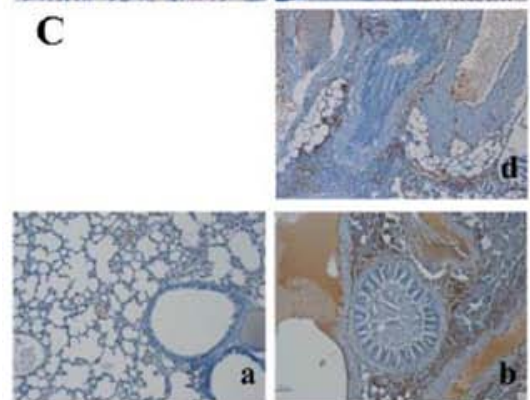

E
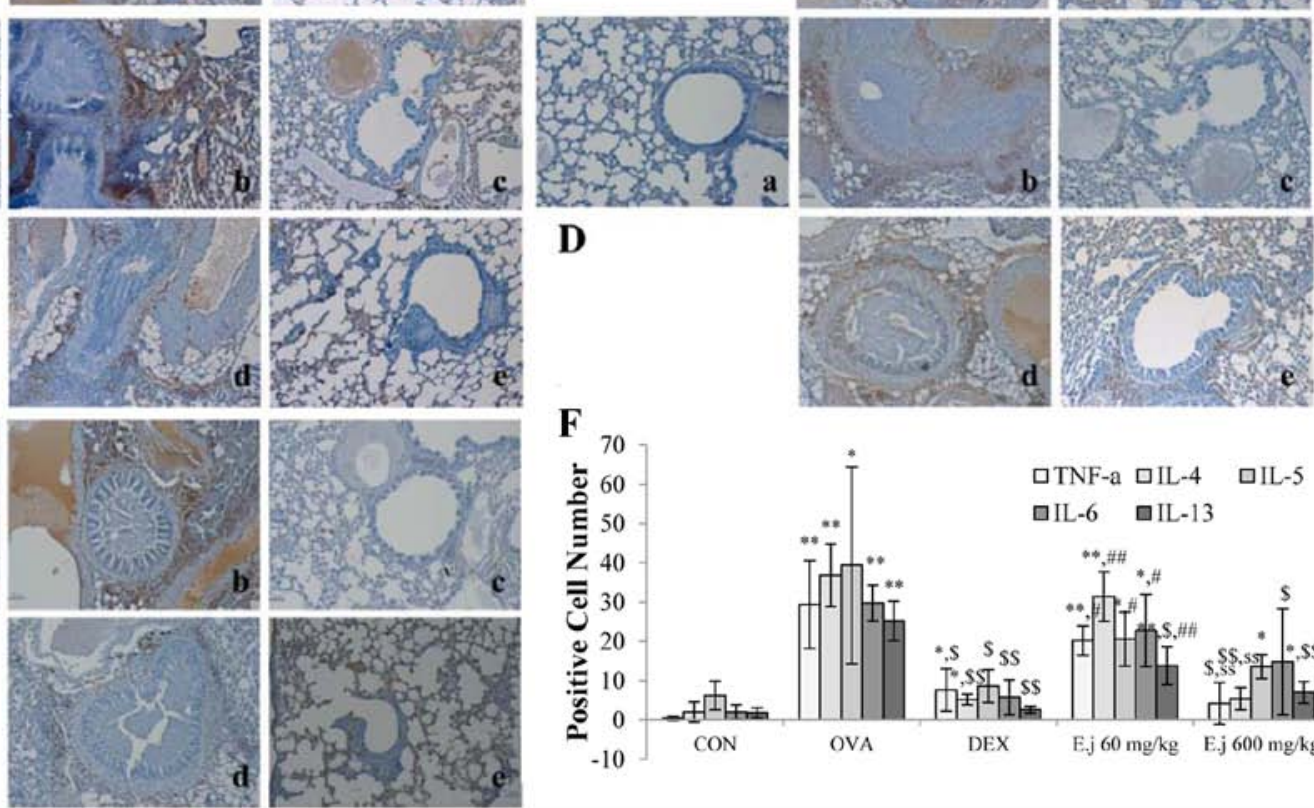

D
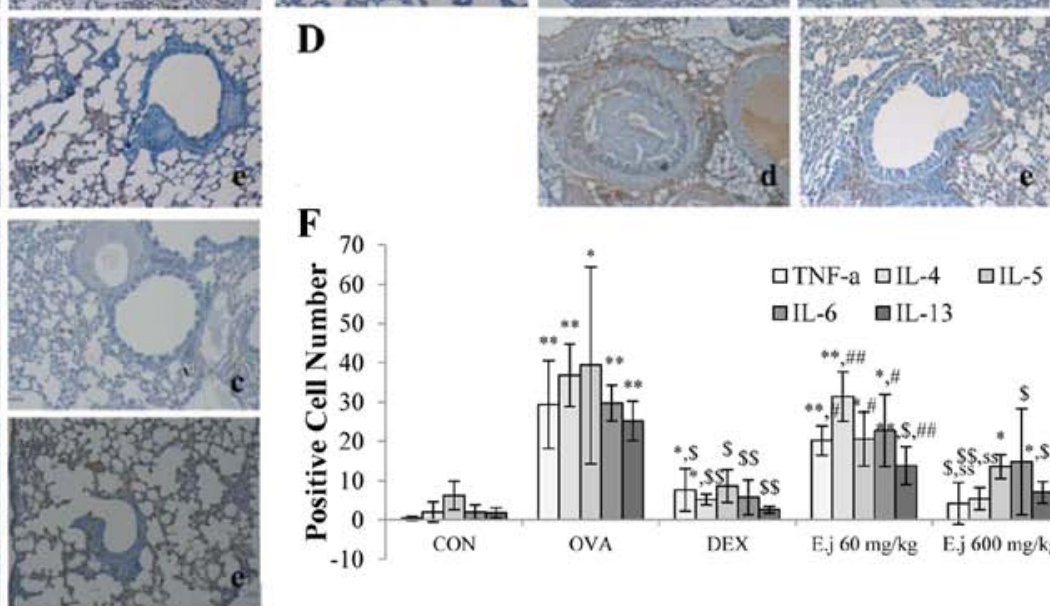

口TNF-a $\square I L-4 \quad \square I L-5$

口IL-6 ㅁIL-13
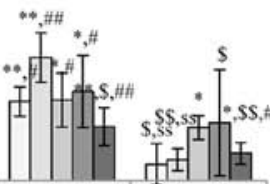

EXX

E.j $60 \mathrm{mg} / \mathrm{kg} \quad$ E.j $600 \mathrm{mg} / \mathrm{kg}$

Figure 6. Effect of E. japonicum on expression of Th2-related cytokines in lung tissue. (A) Representative images of tumor necrosis factor- $\alpha(\text { TNF- } \alpha)^{+}$cells. (B) Representative images of interleukin-4 ( IL-4) ${ }^{+}$cells. (C) Representative images of IL-5 $5^{+}$cells. (D) Representative images of IL- $6^{+}$cells. (E) Representative images of IL-13+ cells. Immunopositive cells were counted in 5 randomly selected, non-overlapping fields (magnification, x200) from 3 separately immunostained lung sections per animal. Treatment groups: panel a, control (CON); panel b, ovalbumin (OVA); panel c, dexamethasone (DEX); panel d, $60 \mathrm{mg} / \mathrm{kg} / \mathrm{day}$ E. japon$i_{\text {cum }}$ (E.j); panel e, $600 \mathrm{mg} / \mathrm{kg} / \mathrm{day}$ E.j. (F) Quantitative analysis of positively-stained cells." $\mathrm{p}<0.05$ vs. CON; ${ }^{* *} \mathrm{p}<0.001$ vs. CON; ${ }^{\$} \mathrm{p}<0.05$ vs. OVA; ${ }^{\$ \$} \mathrm{p}<0.001$ vs. OVA; ${ }^{p}$ < $<0.05$ vs. DEX; ${ }^{\# \#}<0.001$ vs. DEX; ss $<<0.001$ vs. $60 \mathrm{mg} / \mathrm{kg} / \mathrm{day}$ E.j.

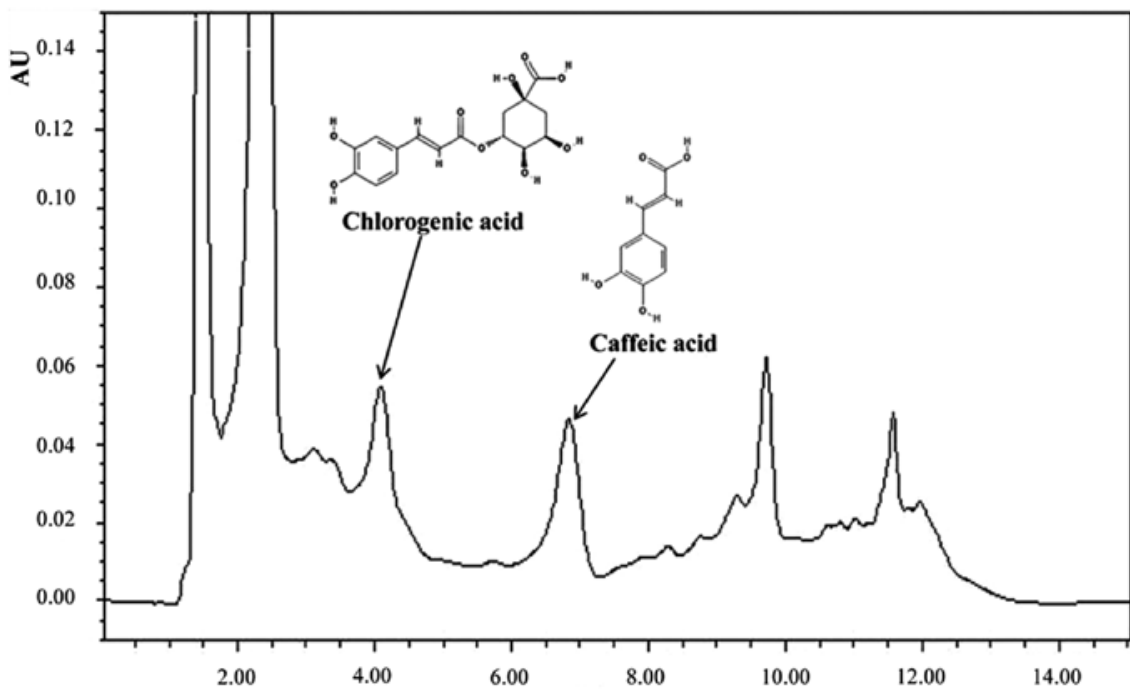

40 Minutes, $0.1299 \mathrm{AU}$

Figure 7. HPLC analysis of E. japonicum. HPLC analysis identified chlorogenic acid and caffeic acid as components of. E. japonicum.

Asthma involves an imbalance between Th1 and Th2 cell-related factors (13), which results in airway hyperrespon- siveness in asthma patients as well as morphological changes in lung tissues such as mucus hypersecretion in the bronchi- 
oles, goblet cell and epithelial cell hyperplasia, and eosinophil infiltration near to the bronchioles and vessels (4). Depending on its severity, asthma may even be fatal (1). Asthma is associated with changes in the expression of Th2- and Th1-related cytokines (13), including the increased expression of IL-4, IL-5, IL-6, IL-13 and TNF- $\alpha$ and the decreased expression of IL-12 (31). In the present study, we found that E. japonicum treatment reversed many of the OVA-induced changes in Th1 and Th2 cell-related factors in a mouse model of asthma, suggesting that E.japonicum may ameliorate the symptoms of asthma by modulating the balance between Th1 and Th2 cells.

The most commonly prescribed drugs for asthma are steroids; however, these have many adverse effects, such as growth inhibition in children (22), cataracts and glaucoma, hypertension, hyperlipidemia, peptic ulcers and myopathy, as well as immunosuppressive effects (23). Moreover, steroids do not cure asthma (20). Therefore, much research has focused on identifying candidate pharmacological agents, including natural products, which are more effective and produce fewer unwanted side-effects than steroids $(32,33)$. The present study suggests that E. japonicum is a promising candidate for the treatment of asthma, although additional studies are warranted in order to improve our understanding of the potential effects of E. japonicum, as well as the mechanisms repsonsible for these effects.

\section{References}

1. World Health Organization. Asthma Fact Sheet No307. November 2013.

2. United States Environmental Protection Agency (EPA). Asthma Facts EPA-402-F-04-019. March 2013.

3. Slejko JF, Ghushchyan VH, Sucher B, Globe DR, Lin SL, Globe $\mathrm{G}$ and Sullivan PW: Asthma control in the United States, 2008-2010: indicators of poor asthma control. J Allergy Clin Immunol 133: 1579-1587, 2014.

4. Kay AB: Allergy and allergic diseases. First of two parts. N Engl J Med 344: 30-37, 2001.

5. National Asthma Education and Prevention Program. Expert Panel Report: Guidelines for the Diagnosis and Management of Asthma Update on Selected Topics - 2002. J Allergy Clin Immunol 110 (Suppl 5): S141-S219, 2002.

6. Mattes J, Yang M, Mahalingam S, Kuehr J, Webb DC, Simson L, Hogan SP, Koskinen A, McKenzie AN, Dent LA, et al: Intrinsic defect in T cell production of interleukin (IL)-13 in the absence of both IL-5 and eotaxin precludes the development of eosinophilia and airways hyperreactivity in experimental asthma. J Exp Med 195: 1433-1444, 2002.

7. Manetti R, Parronchi P, Giudizi MG, Piccinni MP, Maggi E, Trinchieri G and Romagnani S: Natural killer cell stimulatory factor (interleukin 12 [IL-12]) induces T helper type 1 (Th1)-specific immune responses and inhibits the development of IL-4-producing Th cells. J Exp Med 177: 1199-1204, 1993.

8. Szabo SJ, Kim ST, Costa GL, Zhang X, Fathman CG and Glimcher LH: A novel transcription factor, T-bet, directs Th1 lineage commitment. Cell 100: 655-669, 2000.

9. Zhu J, Jankovic D, Oler AJ, Wei G, Sharma S, Hu G, Guo L, Yagi R, Yamane H, Punkosdy G, et al: The transcription factor T-bet is induced by multiple pathways and prevents an endogenous Th2 cell program during Th1 cell responses. Immunity 37: 660-673, 2012 .

10. Brightling CE, Symon FA, Birring SS, Bradding P, Pavord ID and Wardlaw AJ: TH2 cytokine expression in bronchoalveolar lavage fluid $\mathrm{T}$ lymphocytes and bronchial submucosa is a feature of asthma and eosinophilic bronchitis. J Allergy Clin Immunol 110 899-905, 2002.

11. Mosmann TR and Coffman RL: TH1 and TH2 cells: different patterns of lymphokine secretion lead to different functional properties. Annu Rev Immunol 7: 145-173, 1989.
12. Yagi R, Zhu J and Paul WE: An updated view on transcription factor GATA3-mediated regulation of Th1 and Th2 cell differentiation. Int Immunol 23: 415-420, 2011.

13. Barnes PJ: Immunology of asthma and chronic obstructive pulmonary disease. Nat Rev Immunol 8: 183-192, 2008.

14. Hershey GK: IL-13 receptors and signaling pathways: an evolving web. J Allergy Clin Immunol 111: 677-691, 2003.

15. Rankin JA, Picarella DE, Geba GP, Temann UA, Prasad B, DiCosmo B, Tarallo A, Stripp B, Whitsett J and Flavell RA: Phenotypic and physiologic characterization of transgenic mice expressing interleukin 4 in the lung: lymphocytic and eosinophilic inflammation without airway hyperreactivity. Proc Natl Acad Sci USA 93: 7821-7825, 1996.

16. Wills-Karp M, Luyimbazi J, Xu X, Schofield B, Neben TY, Karp CL and Donaldson DD: Interleukin-13: central mediator of allergic asthma. Science 282: 2258-2261, 1998

17. Zhu Z, Homer RJ, Wang Z, Chen Q, Geba GP, Wang J, Zhang Y and Elias JA: Pulmonary expression of interleukin-13 causes inflammation, mucus hypersecretion, subepithelial fibrosis, physiologic abnormalities, and eotaxin production. J Clin Invest 103: 779-788, 1999.

18. Rincon M and Irvin CG: Role of IL-6 in asthma and other inflammatory pulmonary diseases. Int J Biol Sci 8: 1281-1290, 2012.

19. Hamid Q, Shannon J and Martin J: Physiologic basis of respiratory disease. In: Cytokines and Chemokines in Asthma: An Overview. Tulic MK, Fiset PO, Muller Z and Hamid Q (eds). BC Decker Inc. Hamilton, pp453-467, 2005.

20. Bosnjak B, Stelzmueller B, Erb KJ and Epstein MM: Treatment of allergic asthma: modulation of Th2 cells and their responses. Respir Res 12: 114, 2011.

21. Barnes PJ: Current issues for establishing inhaled corticosteroids as the antiinflammatory agents of choice in asthma. J Allergy Clin Immunol 101: S427-S433, 1998.

22. Wise J: Corticosteroids for asthma may suppress growth in children in first year of treatment, researchers say. BMJ 349: g4623, 2014.

23. Ciriaco M, Ventrice P, Russo G, Scicchitano M, Mazzitello G, Scicchitano F and Russo E: Corticosteroid-related central nervous system side effects. J Pharmacol Pharmacother 4 (Suppl 1): S94-S98, 2013.

24. Soon-Kyung Kwon: Erythronium japonicum Yakup. http://www. yakup.com/pharmplus/plus_print.html?nid=3000131250. Last updated March 19, 2014

25. Heo BG, Park YS, Chon SU, Lee SY, Cho JY and Gorinstein S: Antioxidant activity and cytotoxicity of methanol extracts from aerial parts of Korean salad plants. Biofactors 30: 79-89, 2007.

26. Boerjan W, Ralph J and Baucher M: Lignin biosynthesis. Annu Rev Plant Biol 54: 519-546, 2003.

27. Koriem KM and Soliman RE: Chlorogenic and caftaric acids in liver toxicity and oxidative stress induced by methamphetamine. J Toxicol 2014: 583494, 2014

28. Revuelta-Iniesta R and Al-Dujaili EA: Consumption of green coffee reduces blood pressure and body composition by influencing 11 $\beta$-HSD1 enzyme activity in healthy individuals: a pilot crossover study using green and black coffee. BioMed Res Int 2014: 482704, 2014.

29. Kim HR, Lee DM, Lee SH, Seong AR, Gin DW, Hwang JA and Park JH: Chlorogenic acid suppresses pulmonary eosinophilia, IgE production, and Th2-type cytokine production in an ovalbumin-induced allergic asthma: activation of STAT- 6 and JNK is inhibited by chlorogenic acid. Int Immunopharmacol 10: 1242-1248, 2010.

30. Sy LB, Yang LK, Chiu CJ and Wu WM: The immunoregulatory effects of caffeic acid phenethyl ester on the cytokine secretion of peripheral blood mononuclear cells from asthmatic children. Pediatr Neonatol 52: 327-331, 2011.

31. Larché M, Robinson DS and Kay AB: The role of T lymphocytes in the pathogenesis of asthma. J Allergy Clin Immunol 111: 450-463, quiz 464, 2003.

32. Seo JW1, Cho SC, Park SJ, Lee EJ, Lee JH, Han SS, Pyo BS, Park DH and Kim BH: 1'-Acetoxychavicol acetate isolated from Alpinia galanga ameliorates ovalbumin-induced asthma in mice. PLosOne 8: e56447, 2013.

33. Bang MA, Seo JH, Seo JW, Jo GH, Jung SK, Yu R, Park DH and Park SJ: Bacillus subtilis KCTC 11782BP-produced alginate oligosaccharide effectively suppresses asthma via T-helper cell type 2-related cytokines. PLoS One 10: e0117524, 2015. 